\title{
Performance Evaluation of Prototype FBMC Cognitive Radio under Constraints of $L$ Number of Sensing Samples at Variable SNR for AWGN and Rayleigh Fading Environment
}

\author{
Ankur Singh Kang*, Er. Vishal Sharma and Renu Vig \\ Deptt ECE*, UIET, Panjab University Chandigarh, India \\ askang_85@yahoo.co.in
}

\begin{abstract}
Currently, the users are dependent upon the services of a number of wireless access systems which are available till date. Especially, many new systems are capable of using not only the 800-6000 MHz band suitable for broadband wireless access systems and mobile communication but also other frequency bands such VHF and UHF bands. It seems that within a next few years, a majority of frequency bands, suitable for mobile communication systems, 4 are completely used and newer innovative solutions are compulsory. The best possible solution to use is Cognitive Radio technology that is a radio system, able to sense by knowing its situation and regulate its radio operating parameters autonomously as per the collaborating wireless and wired networks. Just to have a judicious use of available frequency spectrum, the cognitive radio is expected as a key technology. The present paper investigates the Performance Evaluation and Analysis of Prototype Filter Bank Mutlicarrier Cognitive radio under the constraints of $L$ number of sensing samples at variable SNR for AWGN and Rayleigh fading Environment.
\end{abstract}

Keywords: OFDM, FBMC, Filter-Bank, Cognitive radio

\section{Introduction}

Cognitive radio being an intelligent wireless communication system is able to dynamically adjust its transmission characteristics, hence it is treated as a possible remedy for getting rid of spectrum scarcity problem by enhancing the spectrum efficiency using multicarrier communication techniques [1]. Multicarrier communication techniques lead to better resource allocation strategies among different secondary users, as primary and secondary user bands persist side by side. With Different Wireless Multiple Access Technologies, the mean mutual interference between the two systems is considered a important factor to evaluate the performance of both the networks. OFDM based CR system is vulnerable to more interference to the PUs due to large side lobes in its filter frequency response. The inclusion of Cyclic Prefix in each OFDM symbol degrades the system capacity. This drastic leakage effect which is predominant in different frequency sub bands bears a negative impact on the performance of FFT based spectrum sensing. So, to curtail this leakage problem in OFDM, a very tight synchronization problem needs to be imposed at the cognitive radio system network level. Filter bank Multicarrier which is basically an OFDM with OQAM pre and post processing in the analysis and synthesis filter banks, need not require any Cyclic prefix extension as it can overcome the spectral leakage problem by reducing the sidelobes of each subcarrier resulting in increased spectral efficiency. Various methods for spectrum sensing using filter bank approach found in literature show the earlier workers making use of Welch Spectral Periodogram technique and Thomson Multitaper method and Lagrangian Multiplier Approach etc have been discussed[2]. The transmit power of each subcarrier should be varied according to

Received (June 7, 2017), Review Result (September 26, 2017), Accepted (September 28, 2017) 
the channel condition and the location of the subcarriers w.r.t Primary user spectrum. The CR system can use the non-active and active Primary User bands as long as the total power and other interference constraints are satisfied [3].

\section{OFDM/FBMC Subchannel Processing}

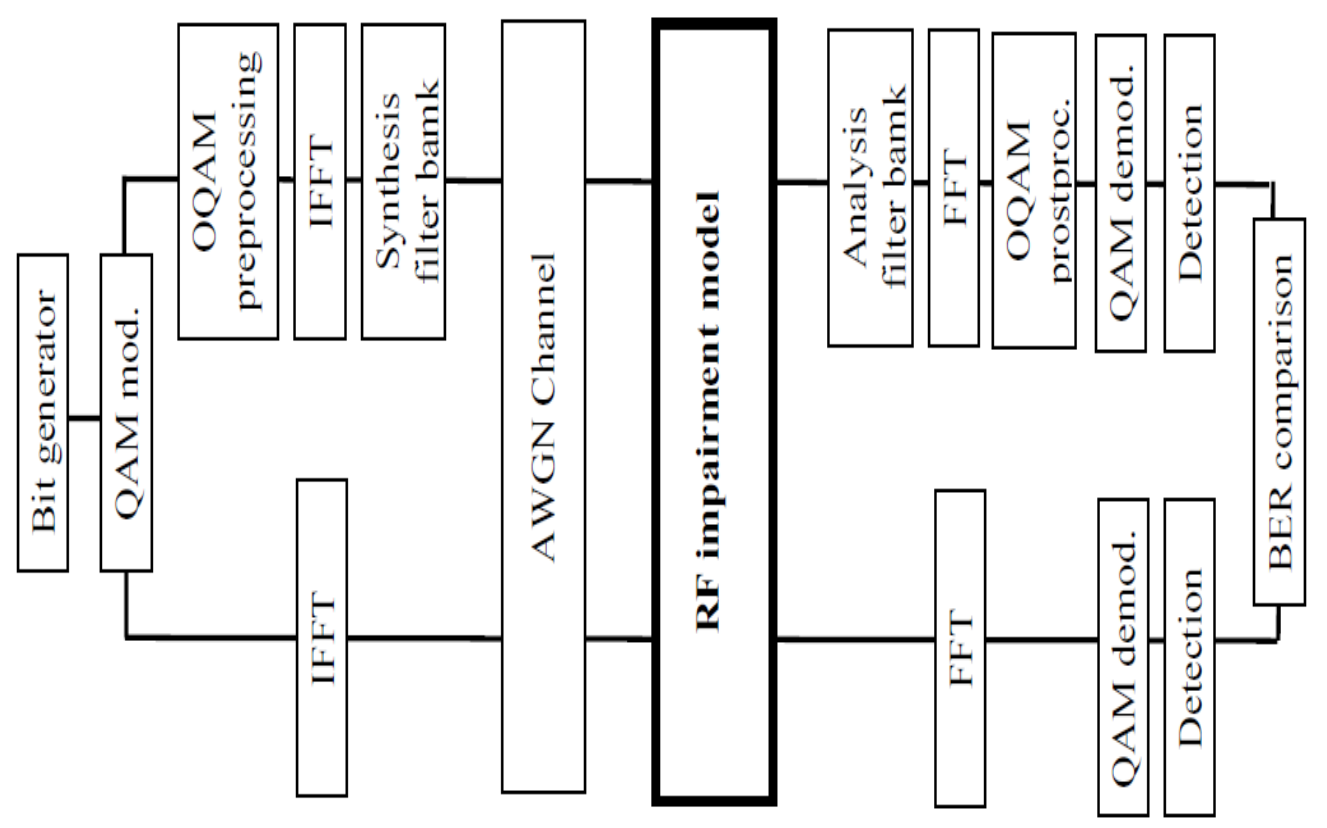

\section{Figure 1. Block Diagram of FBMC/OFDM Baseband Simulation Framework for RF Impairments [4}

The prototype filter should have several essential characteristics like linear-phase Nyquist filter with unity roll-off, to minimize delay and complexity, transmission zeros at the frequencies which are integer multiples of the subchannel spacing, for independent and accurate channel measurements, attenuation increasing with frequency, to offer increasing level of protection from/to primary users in cognitive radio. With these constraints, the main flexibility parameters in the system design are the number of sub channels, and the overlapping factor, which determines the total number of filter coefficients, and the option for partial filter bank design, for example to equip a low rate user in uplink in an efficient manner. The Mirabassi Martin Filter Coefficients have been taken in PHYDAS Report have been taken under consideration in the present study. FBMC with $\mathrm{K}=4$ is designed in PhyDAS Project. FBMCs which are frequency localized prototype filters suffer from minimal intercell interference. Large part of the assigned spectrum is underutilized while the increasing number of wireless multimedia applications lead to spectrum scarcity. Cognitive radio is an option to utilize non used parts of the spectrum that actually are assigned to primary services. The benefits of cognitive radio are clear in the emergency situations. Current emergency services rely much on the public networks. This is not reliable in public networks where the public networks get overloaded. The major limitation of emergency network needs a lot of radio resources. The idea of applying Cognitive Radio to the emergency networks is to alleviate this spectrum shortage problem by dynamically accessing the free spectrum resources. Cognitive Radio is able to work in different frequency bands and various wireless channels and supports multimedia services such as voice, data and video. A reconfigurable radio architecture is proposed to enable the evolution from the traditional software defined radio to Cognitive Radio [5]. 


\section{FBMC Transmission Scheme}

Filter Bank Multicarrier technique is an enhancement to conventional OFDM scheme. The difference between them is that FFT is complemented by a set of digital filters known as poly phase network in FBMC approach while in OFDM approach, a cyclic prefix is inserted after FFT. The drivers for FBMC approach originate from two characteristics mainly time domain and frequency domain. In the time domain, the Cyclic Prefix is avoided which allows for full use of radiated power and achieves an increase in bit rate which can be significant. In the frequency domain, the leakage is very small and users can exploit independent groups of sub channels, in a unsynchronized context. In the transmitter and receiver, a filter bank is obtained by adding to a FFT, a specific signal processing module, the poly phase network, the number $\mathrm{M}$ of the filters in the bank is the size of FFT and the system is said to have M sub channels. The filters are frequency shifted versions of prototype low pass filter, satisfying nyquist criteria. There are different approaches for design of such filters [6].

\subsection{Model Structure of Transmultiplexer}

The core of FBMC/OQAM system is a critically sampled Transmultiplexer (TMUX) configuration shown in Figure 2. The main processing blocks are OQAM pre-processing, Synthesis Filter Bank (SFB), Analysis Filter Bank (AFB) and OQAM post-processing. The transmission channel is typically assumed to be ideal with $C(z)=1$ when analyzing and designing TMUX systems because the channel equalization problem is handled separately. In order to guarantee down sampling at correct phase (at the maximum points of the received pulses), an extra delay $z^{-D}$, with $D$ depending on length of prototype filter

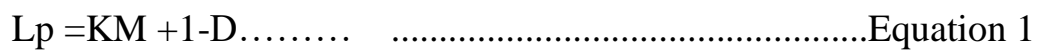

has to be included either to the Synthesis Filter Bank(SFB) output or Analysis Filter Bank (AFB) input. Based on Equation 1 the required extra delay in the TMUX system is $z^{-2}$. A simple implementation method for this delay is to insert an additional zero coefficient to the beginning of the impulse response of the optimized prototype filter.

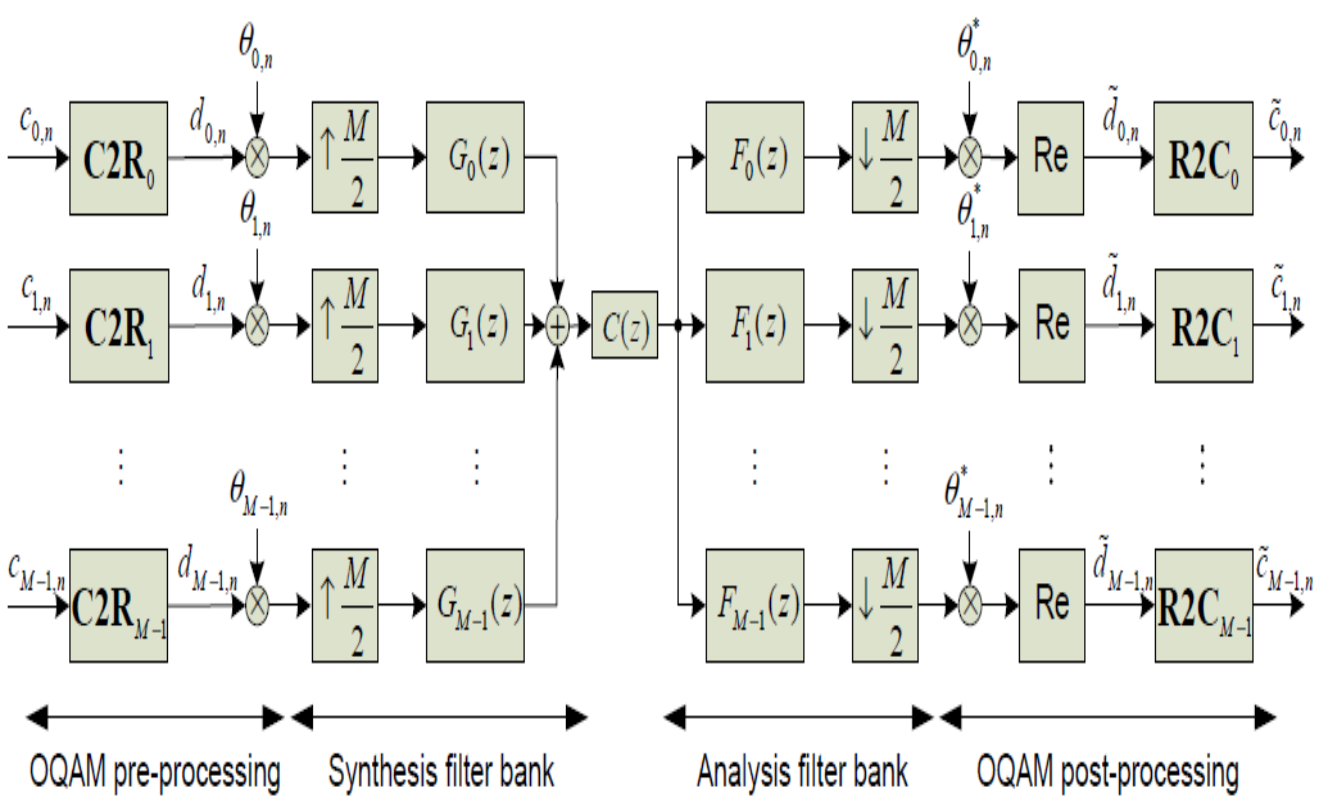

Figure 2. Block Diagram of FBMC-OQAM Processing: TMUX Configuration[7] 


\subsection{Synthesis and Analysis Filter Bank}

In the SFB, the input signals are first up sampled by $M / 2$ and then filtered with synthesis filters $G k(z)$. The SFB output signal is formed when all sub signals are added together. In the AFB, the input signal is first filtered by analysis filters $F k(z)$ and these signals are then down sampled by a factor of $M / 2$ to form output signals. The presented TMUX system can be considered to be critically sampled because the sample rate (counted in terms of real-valued samples) of the SFB output (AFB input) is equal to the sum of the sample rates of the sub channel signals $d k ; n\left(d^{r} k ; n\right)$. In the case of chosen class of complex modulated filter banks, all sub channel filters can be generated from a single real-valued linear-phase FIR low pass prototype filter $p[m]$ by using exponential modulation as follows [7-8].

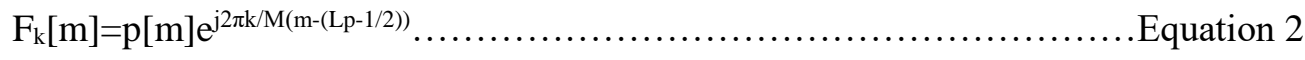

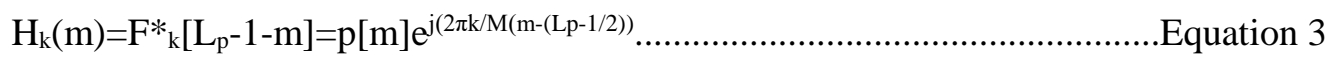

where $k=0 ; 1 \ldots . M-1$ and $m=0 ; 1 \ldots . . L p-1$.Due to the modulation function, the resulting sub channel filters also have a linear phase. The magnitude response of the prototype filter is divided into three types of regions: the pass band region is $\left[0 ; \omega_{p}\right]$, the stop band region is $\left[\omega_{s} ; \mathrm{p}\right]$, and the gap between these two is called as the transition band. The band edges can be given as follows $\omega_{p}=(1-\alpha) \pi / M$ and $\omega_{s}=(1+\alpha) \pi / M$, where $\alpha$ is the roll off factor that defines how much adjacent sub channels are overlapping. A typical choice is $\alpha=1: 0$, which means that the transition bands of a sub channel end at the centers of the adjacent sub channels[9]. OQAM pre processing and post processing operation involves complex to real and real to complex conversion of the two symbols. In the first operation, there is an increase in sample rate by a factor of two while in the later case there is a decrease in the sample rate by a factor of two[10-11].

\section{Performance Analysis of Energy Detection FBMC CR under AWGN Channel}

This section shows the simulation analysis for Filter Bank Multicarrier Cognitive radio using Energy Detection Optimization algorithm to sense the spectrum for autonomic communication and opportunistic access under AWGN fading channel environment. Figure.3 shows the Flowchart for plotting SNR versus Probability of Detection under AWGN channel with QPSK Modulation. The input SNR values are initialized for AWGN channel within a range $-20 \mathrm{~dB}$ to $-12 \mathrm{~dB}$. Thereafter, QPSK modulation is applied with variation in Modulation order $M$ over values,4, 8,16,32,64,128,256,512,1024. Different simulations are done in which primary signal will be transmitted for each snr value. The number of times signal detected will lead to the Probability of Detection. The Probability of False Alarm is varied from 0.01 to 0.05 . The effect of noise variance or SNR can be seen on threshold value depending upon the energy level of signal sensed being greater than threshold to indicate the Primary User Detection by Secondary user, otherwise not. Hence, the different values of probability of Detection w.r.t different SNR can be calculated and ultimately, plotted after $10^{\wedge} 3$ Iterations in different Monte Carlo simulation runs. Tables 1,2 and 3 show the values of probabilities of detection and missed detection obtained for $\mathrm{SNR}=-20,-16$ and $-12 \mathrm{~dB}$ respectively. 


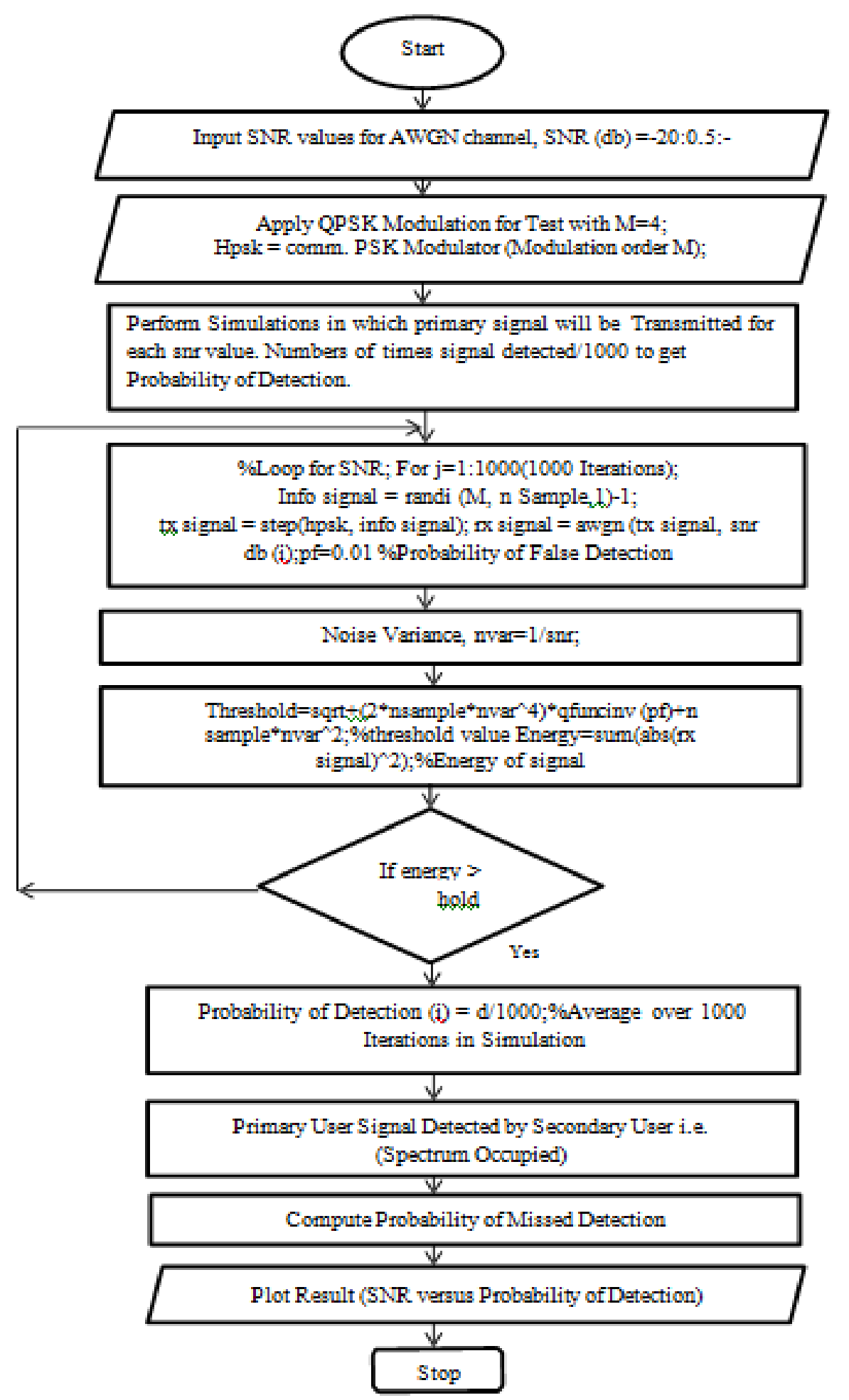

Figure 3. Flowchart for SNR versus Probability of Detection under AWGN Channel using QPSK Modulation 


\subsection{Results\& Discussion}

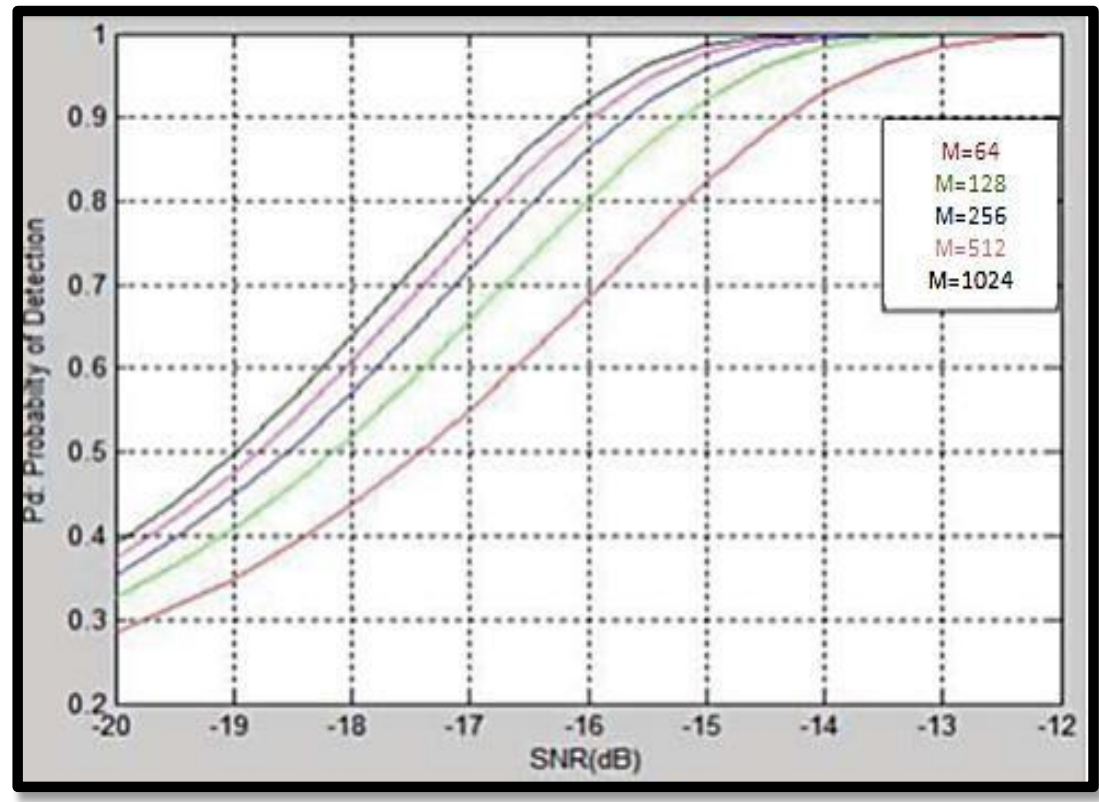

Figure 4. Probability of Detection versus SNR at Variable M

Table 1. Probability of Detection, Probability of False Alarm Values for Different Signal Samples at SNR=-20 dB

\begin{tabular}{|c|c|c|c|c|c|c|}
\hline M & SNR(dB) & $\begin{array}{c}\text { Number of } \\
\text { Samples in a } \\
\text { signal }\end{array}$ & $\begin{array}{c}\text { Number of } \\
\text { Iterations in } \\
\text { Monte Carlo } \\
\text { Simulation }\end{array}$ & $\begin{array}{c}\text { Probability } \\
\text { of } \\
\text { Detection }\end{array}$ & $\begin{array}{c}\text { Probability } \\
\text { of Missed } \\
\text { Detection = } \\
\text { 1- } \\
\text { Probability of } \\
\text { Detection }\end{array}$ & $\begin{array}{c}\text { Probability of } \\
\text { False Alarm }\end{array}$ \\
\hline 64 & -20 & 1000 & $10^{\wedge} 3$ & 0.28 & 0.72 & 0.01 \\
\hline 128 & -20 & 500 & $10^{\wedge} 3$ & 0.32 & 0.68 & 0.05 \\
\hline 256 & -20 & 1000 & $10^{\wedge} 3$ & 0.36 & 0.64 & 0.01 \\
\hline 512 & -20 & 500 & $10^{\wedge} 3$ & 0.38 & 0.62 & 0.05 \\
\hline 1024 & -20 & 1000 & $10^{\wedge} 3$ & 0.4 & 0.6 & 0.01 \\
\hline
\end{tabular}

Table 2. Probability of Detection, Probability of False Alarm Values for Different Signal Samples at SNR=-16 dB

\begin{tabular}{|c|c|c|c|c|c|c|}
\hline M & SNR(dB) & $\begin{array}{c}\text { Number } \\
\text { of } \\
\text { Samples } \\
\text { in a signal }\end{array}$ & $\begin{array}{c}\text { Number of } \\
\text { Iterations in } \\
\text { Monte Carlo } \\
\text { Simulation }\end{array}$ & $\begin{array}{c}\text { Probabilit } \\
\text { y of } \\
\text { Detection }\end{array}$ & $\begin{array}{c}\text { Probability of } \\
\text { Missed } \\
\text { Detection } \\
\text { 1- Probability of } \\
\text { Detection }\end{array}$ & $\begin{array}{c}\text { Probability of } \\
\text { False Alarm }\end{array}$ \\
\hline 64 & -16 & 1000 & $10^{\wedge} 3$ & 0.68 & 0.32 & 0.01 \\
\hline 128 & -16 & 500 & $10^{\wedge} 3$ & 0.8 & 0.2 & 0.05 \\
\hline 256 & -16 & 1000 & $10^{\wedge} 3$ & 0.86 & 0.14 & 0.01 \\
\hline 512 & -16 & 500 & $10^{\wedge} 3$ & 0.9 & 0.1 & 0.05 \\
\hline 1024 & -16 & 1000 & $10^{\wedge} 3$ & 0.93 & 0.07 & 0.01 \\
\hline
\end{tabular}




\section{Table 3. Probability of Detection, Probability of False Alarm Values for Different Signal Samples at SNR=-12 dB}

\begin{tabular}{|c|c|c|c|c|c|c|}
\hline M & SNR(dB) & $\begin{array}{c}\text { Number of } \\
\text { Samples in } \\
\text { a signal }\end{array}$ & $\begin{array}{c}\text { Number of } \\
\text { Iterations } \\
\text { in Monte } \\
\text { Carlo } \\
\text { Simulation }\end{array}$ & $\begin{array}{c}\text { Probability of } \\
\text { Detection }\end{array}$ & $\begin{array}{c}\text { Probability of } \\
\text { Missed } \\
\text { Detection = } \\
\text { - Probability } \\
\text { of Detection }\end{array}$ & $\begin{array}{c}\text { Probability } \\
\text { of False Alarm }\end{array}$ \\
\hline 64 & -12 & 1000 & $10^{\wedge} 3$ & 1 & 0 & 0.01 \\
\hline 128 & -12 & 500 & $10^{\wedge} 3$ & 1 & 0 & 0.05 \\
\hline 256 & -12 & 1000 & $10^{\wedge} 3$ & 1 & 0 & 0.01 \\
\hline 512 & -12 & 500 & $10^{\wedge} 3$ & 1 & 0 & 0.05 \\
\hline 1024 & -12 & 1000 & $10^{\wedge} 3$ & 1 & 0 & 0.01 \\
\hline
\end{tabular}

With increase in value of modulation order $M$ from 4 to 1024 , with the number of samples in a signal $=500,1000$ and number of iterations $=10^{\wedge} 3$, the probability of detection varies from 0 to 1 in small incremental steps of $0.28,0.32,0.36,0.38,0.4,1$ while the values of probability of false detection are 0.01,0.05 within the SNR range of -20db to $12 \mathrm{db}$.From better spectrum sensing viewpoint in energy detection, the probability of false detection is high at low snr and vice versa while probability of detection of Primary User by Secondary User is high at high SNR range. Moreover, it is clear from Figure 4.35, that as M order increases from 64 to 1024 then value of probability of detection keeps on increasing with constant decrease in the value of probability of missed detection from 0.72 at $\mathrm{M}=64$ to 0.6 at $\mathrm{M}=1024$ with $\mathrm{SNR}=-20 \mathrm{~dB}$ which is good trend from FBMC cognitive radio sensing point of view. At $\mathrm{SNR}=-16 \mathrm{~dB}$, the probability of detection increases from 0.68 at $\mathrm{M}=64$ to 0.93 at $\mathrm{M}=1024$, while probability of missed detection reduces from 0.32 at $M=64$ to 0.07 at $M=1024$. At $S N R=-12 d B$, the probability of detection is almost unity as $\mathrm{M}$ varies from 64 to 1024 which implies that higher the SNR range, higher the probability of detection of Primary User by secondary user. Hence, better the spectrum sensing using energy detection approach is achieved.

\subsection{Performance Analysis of Energy Detection Cognitive Radio under Rayleigh Fading Channel with the constraints of $L$ Number of Sensing Samples and Variable SNR}

The Performance Parameters taken under Consideration are Probability of False Alarm and Probability of Missed Detection when the code is run for different number of Iterations for Monte Carlo Simulation. The time bandwidth product $\mathrm{u}=\mathrm{L} . / 2$ is calculated Further, plots between $\mathrm{L}=10,20,15,25,30,50,100$ number of sensing samples and $\mathrm{SNR}(\mathrm{dB})=0,5,10,20$ are obtained. Also L number of sensing samples versus SNR plot is obtained for Performance Analysis of Energy Detection Spectrum Sensing using BPSK as the applied Modulation Technique. The different ROC curves for Probability of False Alarm and Probability of Missed Detection are plotted which indicate the detection threshold value for each individual SNR*L/2 product. The code simulated the energy detection in the cognitive radio when Rayleigh flat-fading channel is used for sensing with the following assumptions.

1. Primary signal is of deterministic nature and binary phase-shift-keying is modulation used.

2. A real Gaussian Noise is there with mean zero and variance one.

The value of the probability of detection for Rayleigh channel can be calculated by taking average of the probability of detection for AWGN channel, which is given as below. 
Pd_theory_awgn=marcumq $\left(\operatorname{sqrt}\left(\mathrm{L}^{*} \mathrm{snr}\right)\right.$,

sqrt(thresh),L./2)

Equation 4

Figure 5 shows flowchart for ROC curves of Probability of False Alarm, Probability of Detection.

\subsubsection{Results and Discussion}

The results obtained are compared with those obtained by Sanket.Kalamkar,2013[8]. The ROC curves have been plotted using command plot(Pf,Pd.Theory,'b0') to analyze the Probability of False Alarm and Probability of Missed Detection. $\mathrm{SNR}=10 .^{\wedge}\left(\mathrm{snr} \_\mathrm{db}\right) / 10$ i.e., snr in linear scale.

\section{Table 4. Probability of False Alarm, Probability of Missed Detection Values} at Different Sensing Samples, Variable SNR

\begin{tabular}{|c|c|l|c|c|c|c|}
\hline $\begin{array}{c}\text { L number } \\
\text { of Sensing } \\
\text { samples }\end{array}$ & SNR(dB) & $\begin{array}{l}\text { Probability of } \\
\text { False Alarm }\end{array}$ & $\begin{array}{c}\text { Probability of } \\
\text { Detection }\end{array}$ & $\begin{array}{c}\text { Probability of } \\
\text { Missed } \\
\text { Detection=1- } \\
\text { Probability of } \\
\text { Detection }\end{array}$ & $\begin{array}{c}\text { Number of } \\
\text { Iterations for } \\
\text { Monte Carlo } \\
\text { Simulations }\end{array}$ & $\begin{array}{c}\text { Time- } \\
\text { Bandwidth } \\
\text { Product u=L./2 }\end{array}$ \\
\hline 10 & 0 & $0.01: 0.03: 1$ & 0.3 & 0.7 & $10^{\wedge} 5$ & 5 \\
\hline 20 & 0 & $0.01: 0.05: 1$ & 0.42 & 0.58 & $10^{\wedge} 5$ & 10 \\
\hline 20 & 5 & $0.01: 0.05: 1$ & 0.74 & 0.26 & $10^{\wedge} 5$ & 10 \\
\hline 15 & 10 & $0.01: 0.05: 1$ & 0.89 & 0.11 & $10^{\wedge} 5$ & 7.5 \\
\hline 25 & 20 & $0.01: 0.05: 1$ & 0.99 & 0.1 & $10^{\wedge} 5$ & 12.5 \\
\hline 30 & 5 & $0.01: 0.05: 1$ & 0.79 & 0.21 & $10^{\wedge} 5$ & 15 \\
\hline 30 & 5 & $0.01: 0.05: 1$ & 0.82 & 0.18 & $10^{\wedge} 3$ & 15 \\
\hline 50 & 10 & $0.01: 0.05: 1$ & 0.96 & 0.4 & $10^{\wedge} 3$ & 25 \\
\hline 100 & 20 & $0.01: 0.05: 1$ & 0.99 & 0.1 & $10^{\wedge} 3$ & 50 \\
\hline
\end{tabular}

Table 5. Probability of False Alarm, Probability of Detection values for $L=30$ Sensing Samples at SNR $=5 \mathrm{~dB}$

\begin{tabular}{|c|c|c|}
\hline Probability of False Alarm & Probability of Detection & $\begin{array}{c}\text { Probability of MissDetection=1- } \\
\text { Probability of Detection }\end{array}$ \\
\hline 0.1 & 0.86 & 0.14 \\
\hline 0.3 & 0.93 & 0.7 \\
\hline 0.5 & 0.96 & 0.4 \\
\hline 0.7 & & 0.2 \\
\hline & 0.98 & 0 \\
\hline & & \\
\hline
\end{tabular}


Table 6. Probability of False Alarm, Probability of Detection values for $L=50$

Sensing Samples at SNR=10 dB

\begin{tabular}{|c|c|c|}
\hline Probability of False Alarm & Probability of Detection & $\begin{array}{c}\text { Probability of Missed Detection=1- } \\
\text { Probability of Detection }\end{array}$ \\
\hline 0 & 0.94 & 0.06 \\
\hline 0.2 & 0.978 & 0.022 \\
\hline 0.4 & 0.987 & 0.013 \\
\hline 0.6 & 0.993 & 0.007 \\
\hline 0.8 & 0.997 & 0.003 \\
\hline
\end{tabular}

Table 7. Probability of False Alarm, Probability of Detection values for $L=25$ Sensing Samples at SNR $=20 \mathrm{~dB}$

\begin{tabular}{|c|c|c|}
\hline Probability of False Alarm & Probability of Detection & $\begin{array}{c}\text { Probability of Missed Detection=1- } \\
\text { Probability of Detection }\end{array}$ \\
\hline 0.1 & 0.995 & 0.005 \\
\hline 0.3 & 0.997 & 0.003 \\
\hline 0.5 & 0.998 & 0.002 \\
\hline 0.7 & 0.999 & 0.001 \\
\hline 0.9 & 1 & 0 \\
\hline
\end{tabular}

Table 8. Probability of False Alarm, Probability of Detection values for $L=100$ Sensing Samples at SNR=20 dB

\begin{tabular}{|c|c|c|}
\hline Probability of False Alarm & Probability of Detection & $\begin{array}{c}\text { Probability of Missed Detection=1- } \\
\text { Probability of Detection }\end{array}$ \\
\hline 0.2 & 0.999 & 0.001 \\
\hline 0.3 & 0.998 & 0.002 \\
\hline 0.4 & 0.997 & 0.003 \\
\hline 0.5 & 1 & 0 \\
\hline 0.8 & 1 & 0 \\
\hline & & \\
\hline
\end{tabular}




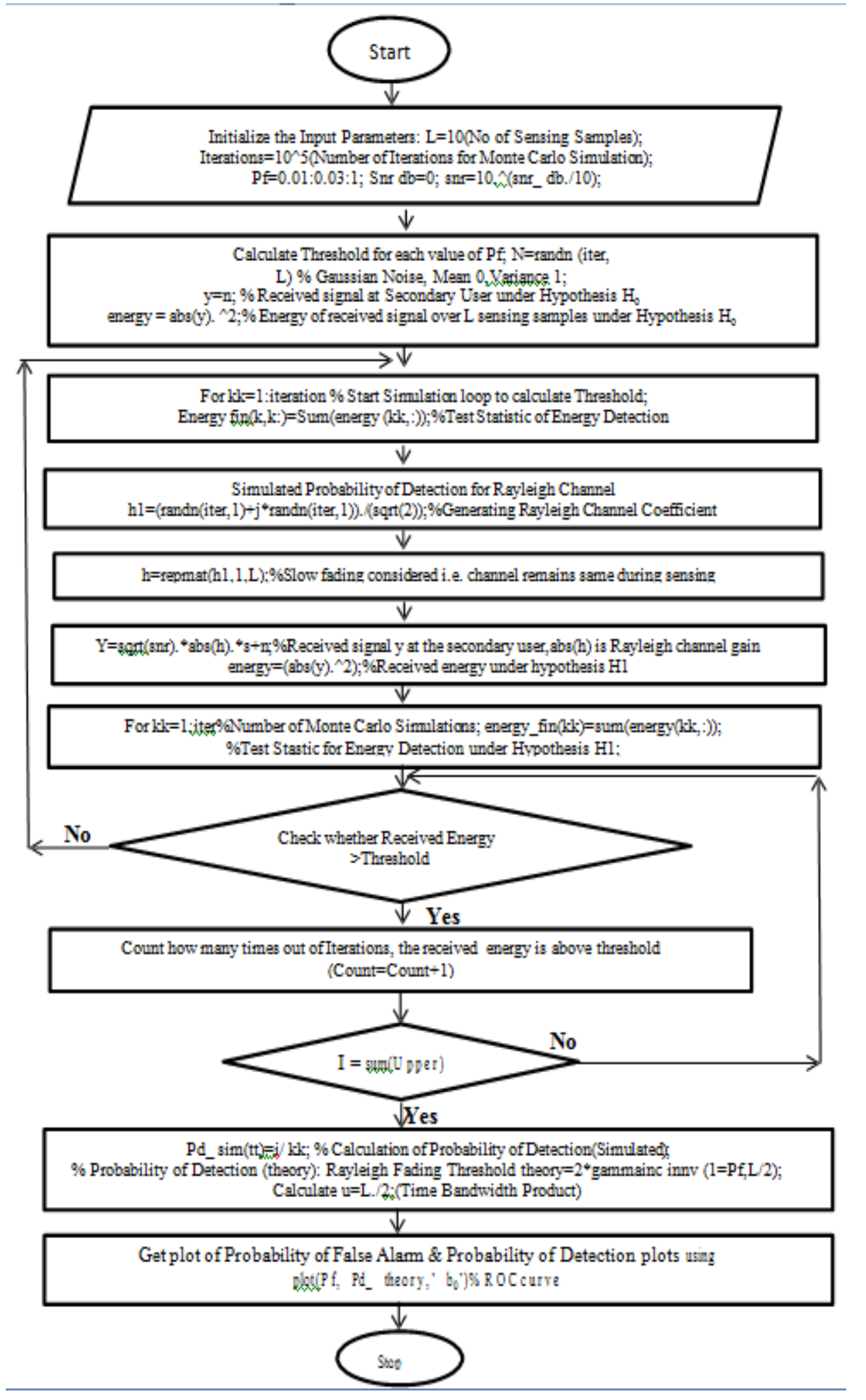

Figure 5. Flowchart for ROC curves of Probability of False Alarm and Probability of Detection under Rayleigh Channel 


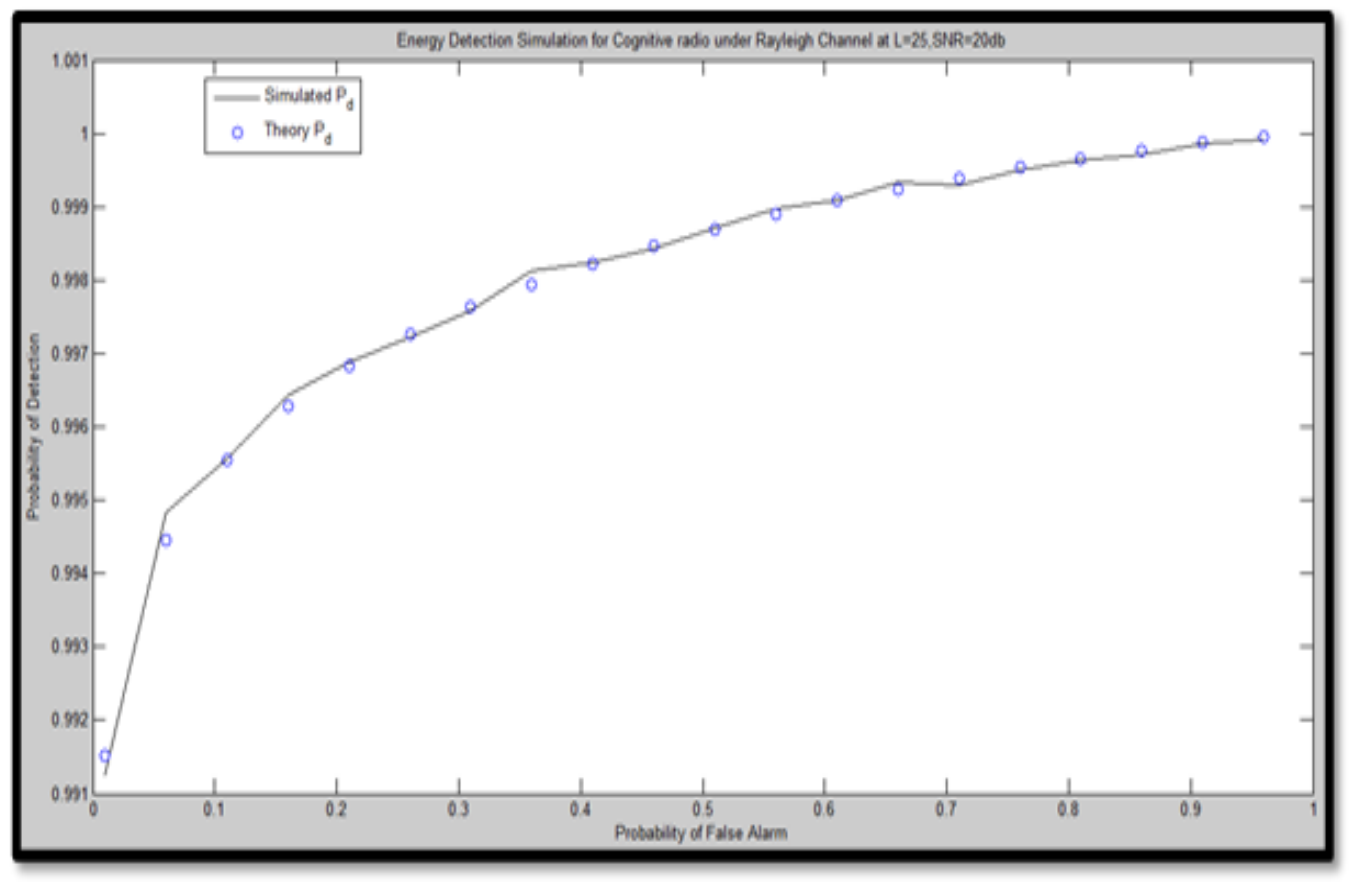

Figure 6. Pd versus Pfa at $L=25, S N R=20 d b$

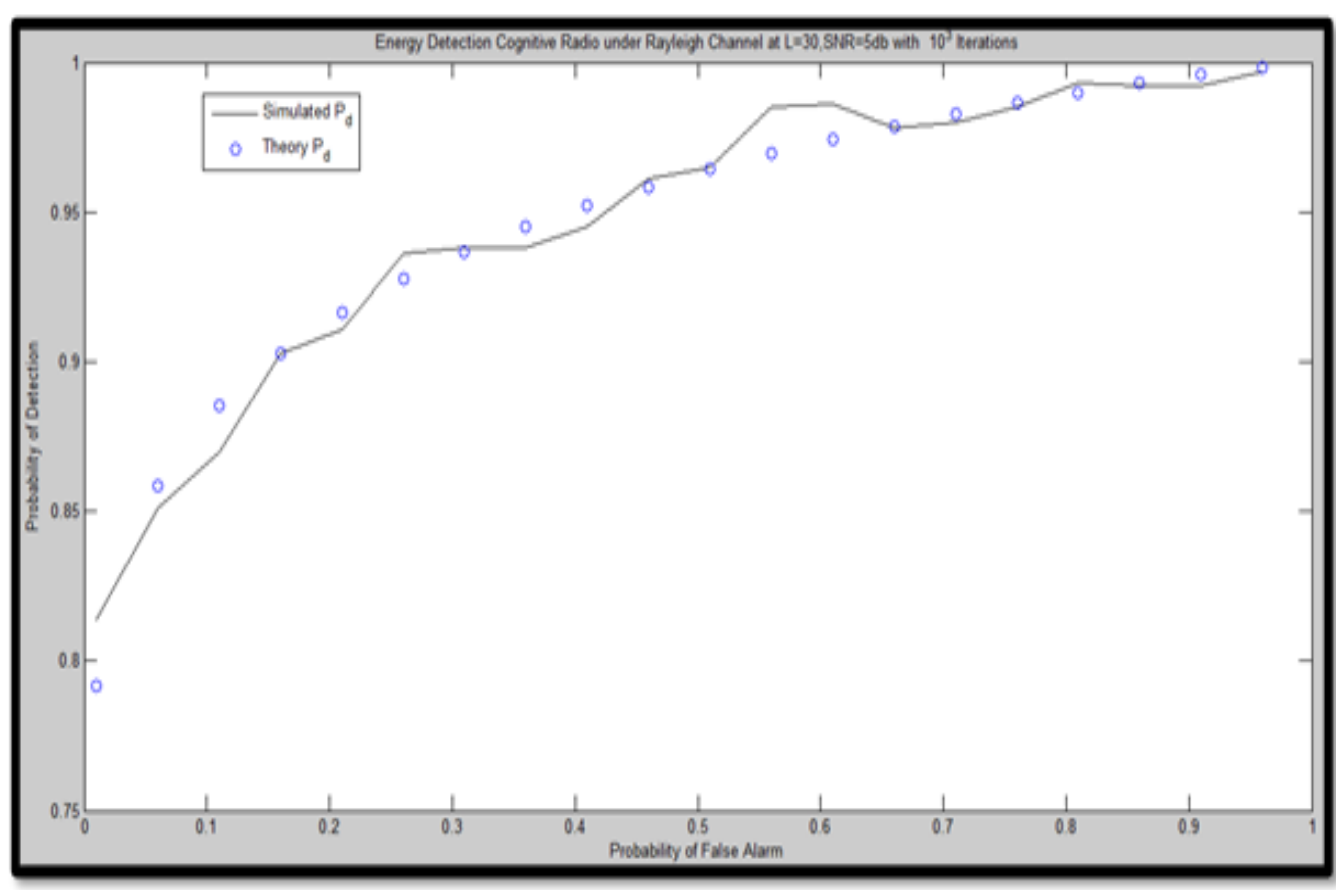

Figure 7. Pd Versus Pfa at $L=30, S N R=5 d b$, Number of Iterations $=10^{\wedge} 3$ 


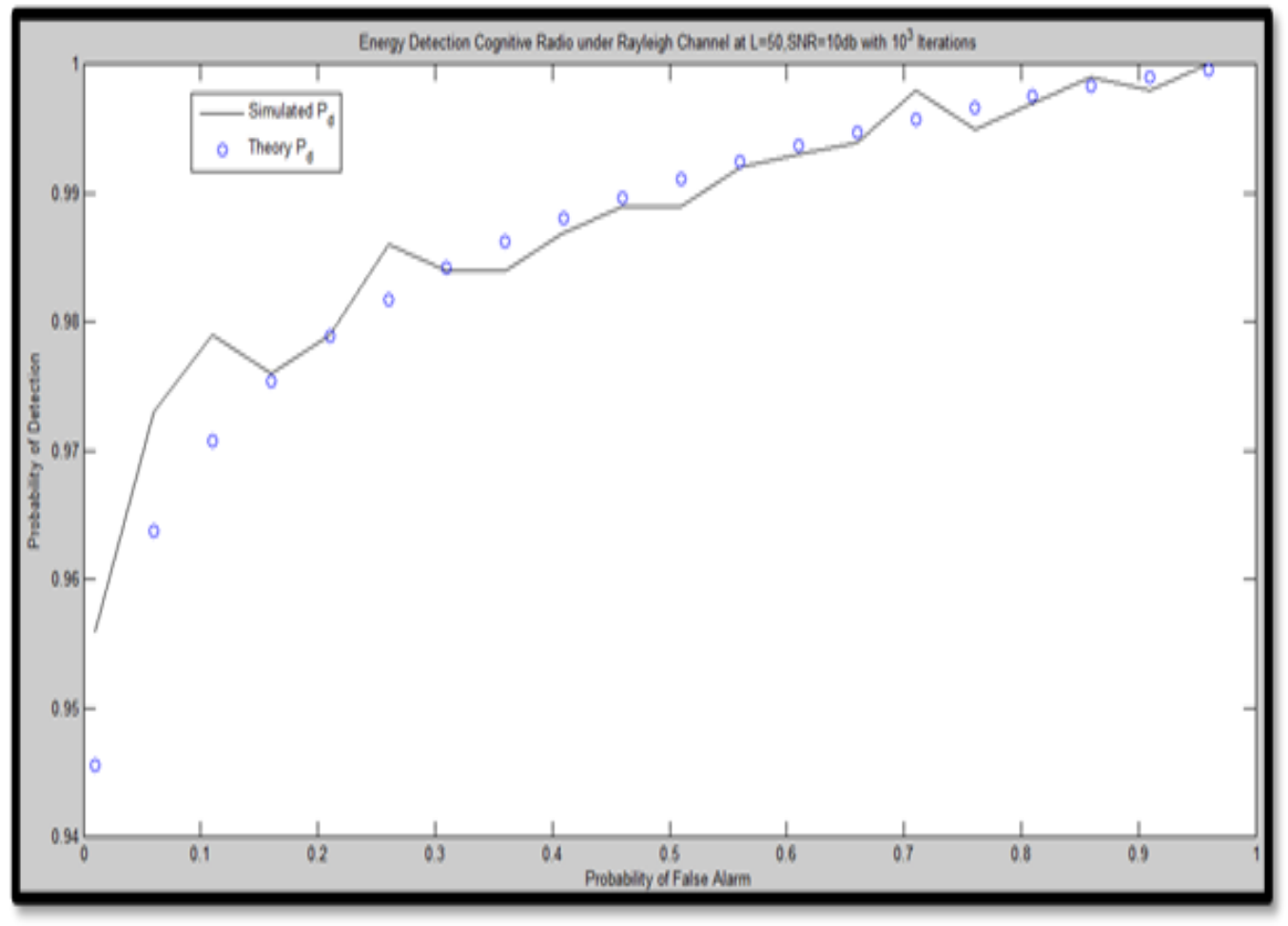

Figure 8. PD Versus PFA at $L=50, S N R=10 \mathrm{db}$, Number of Iterations $=10^{\wedge} 3$

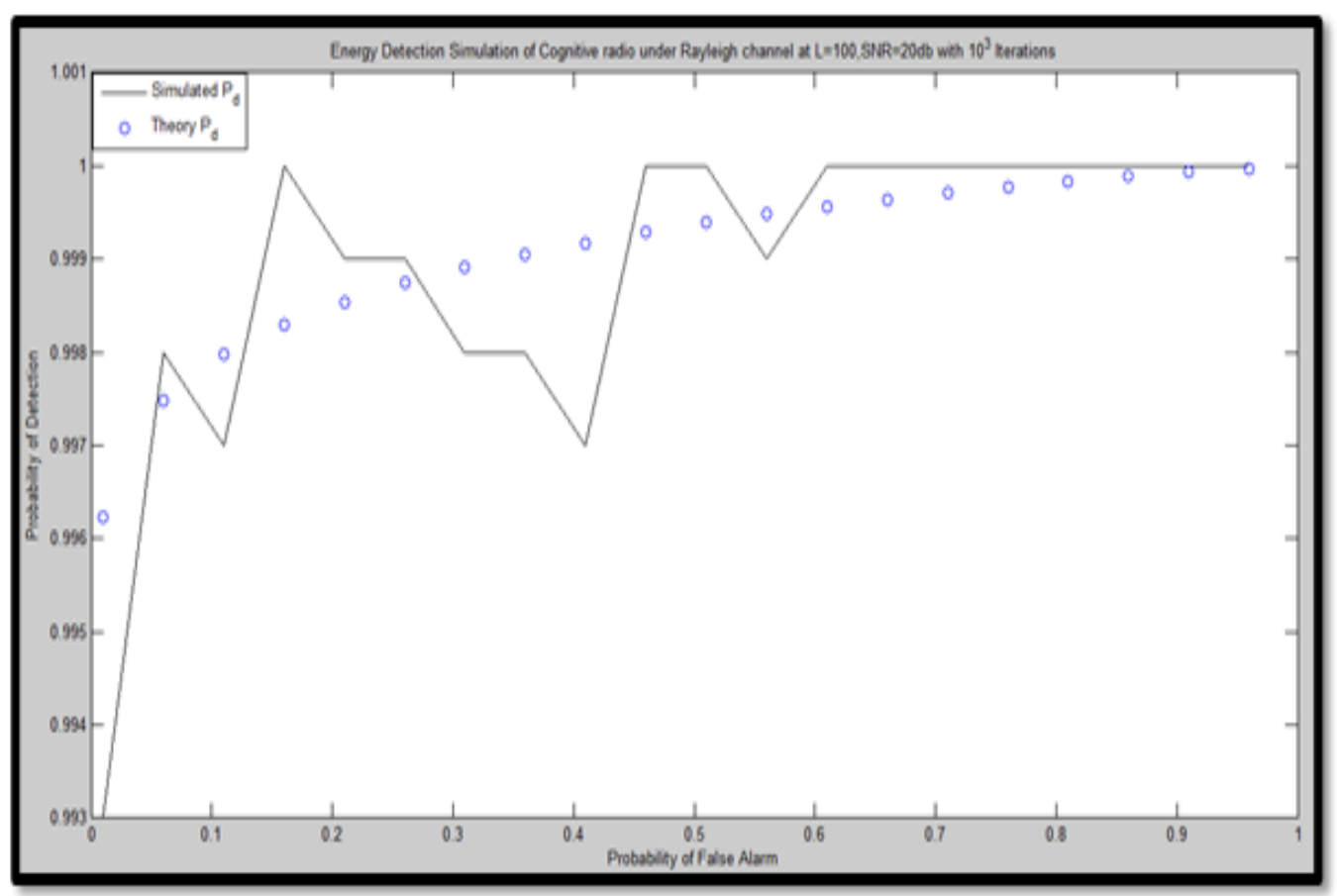

Figure 9. PD versus PFA at $L=100, S N R=20 \mathrm{db}$, Number of Iterations $=10^{\wedge} 3$ 


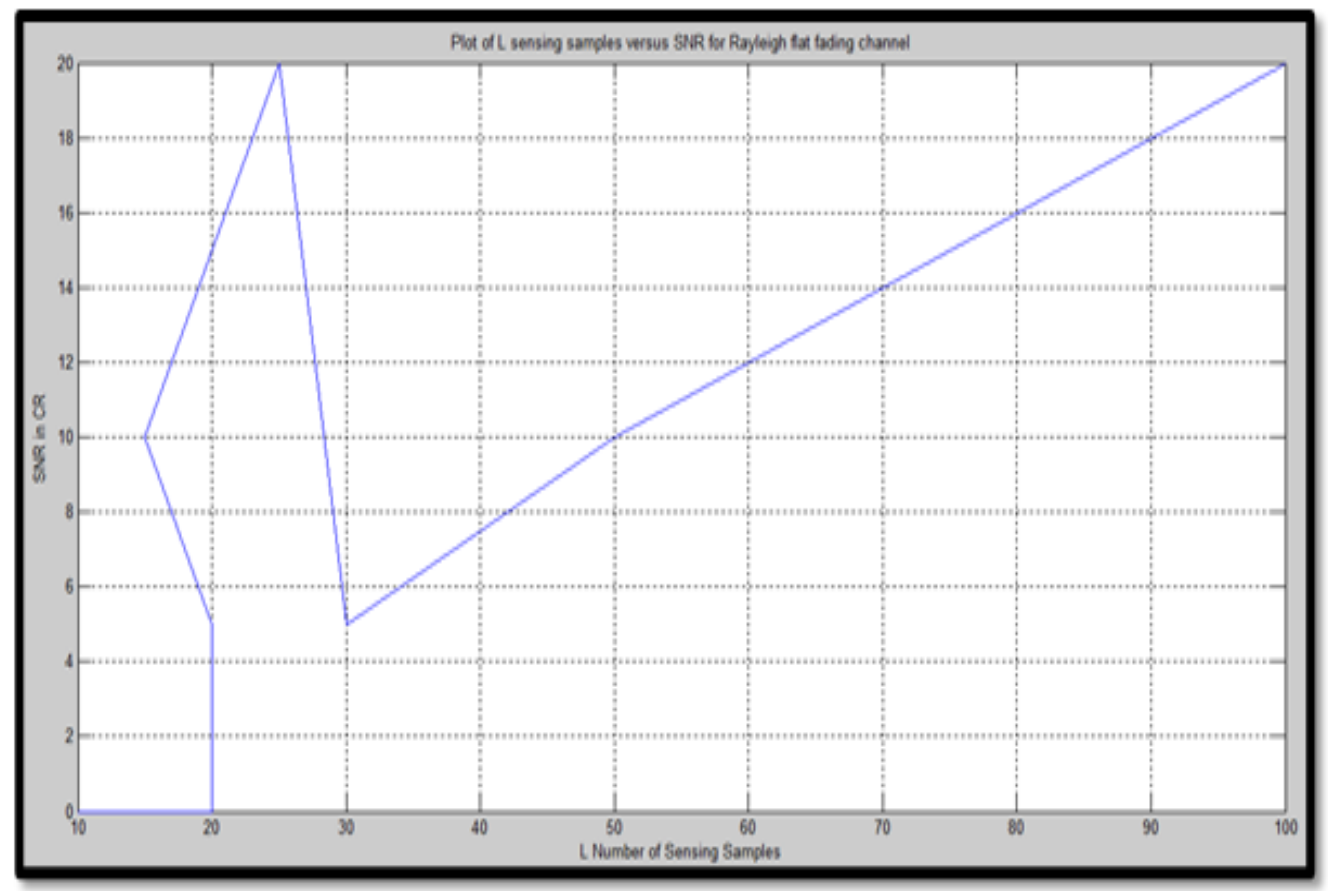

Figure 10. Plot of L Number of Sensing Samples versus SNR for Rayleigh Channel

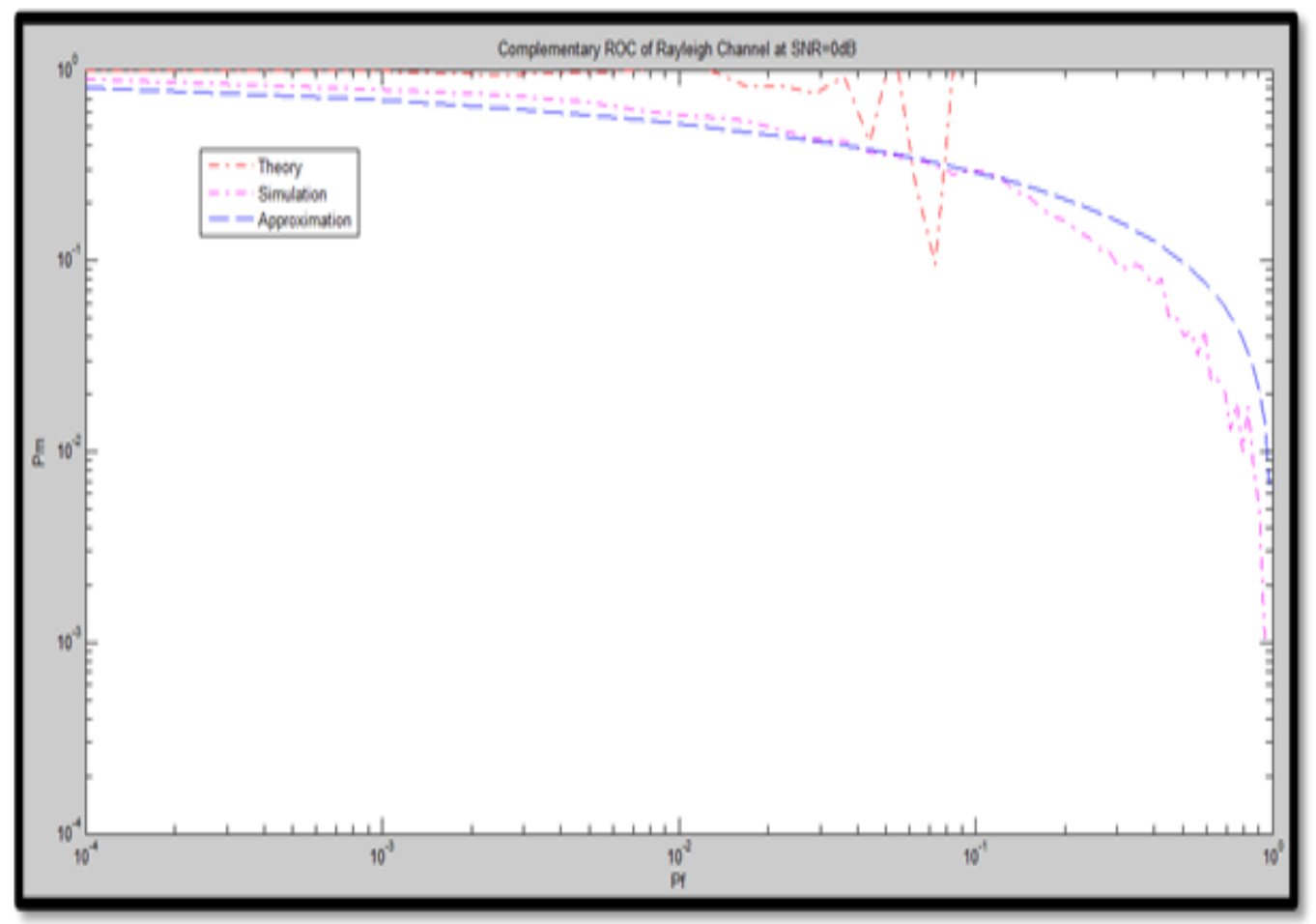

Figure 11. PM versus PF for Rayleigh Channel at SNR=0dB 


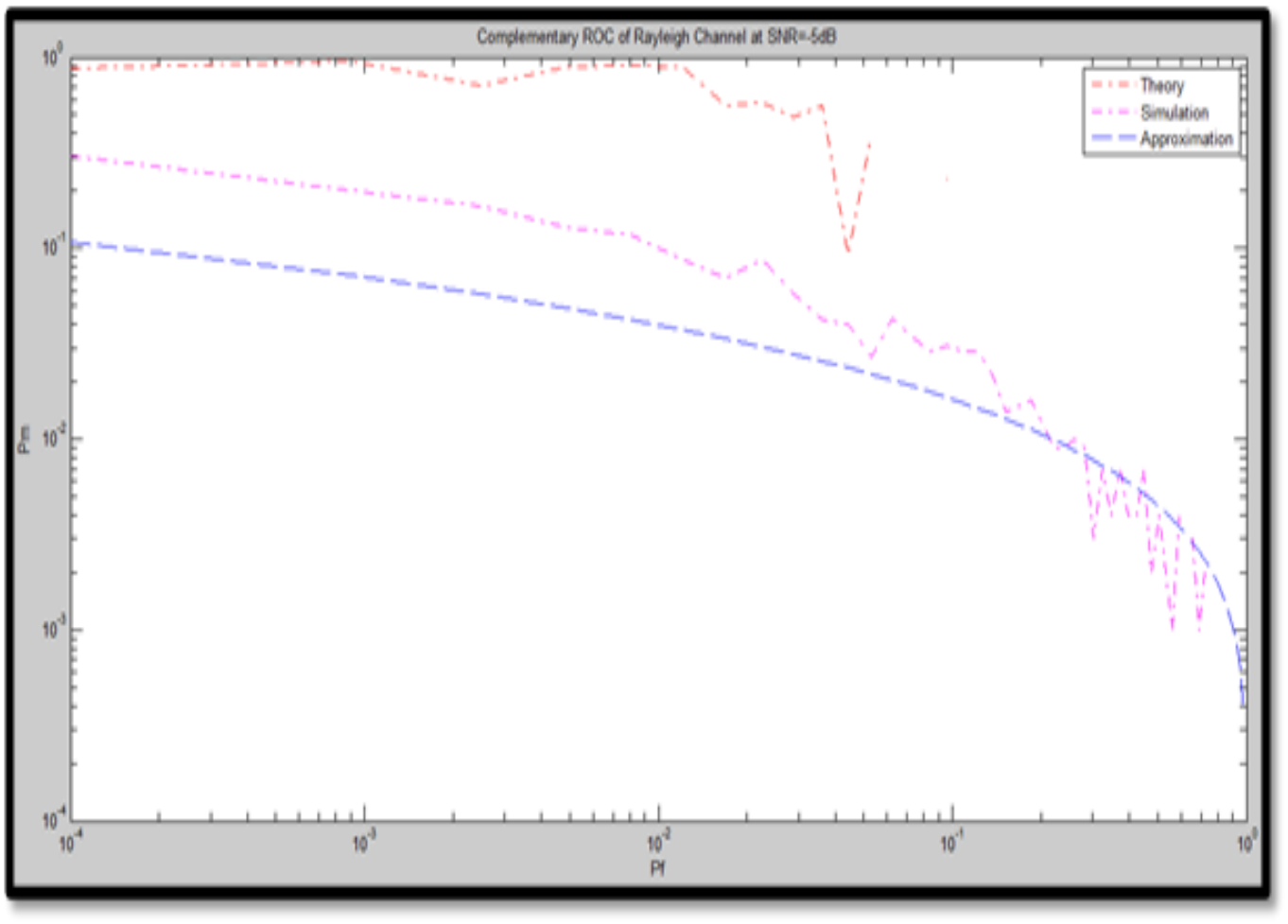

Figure 12. PM versus PF for Rayleigh Channel at SNR=-5dB

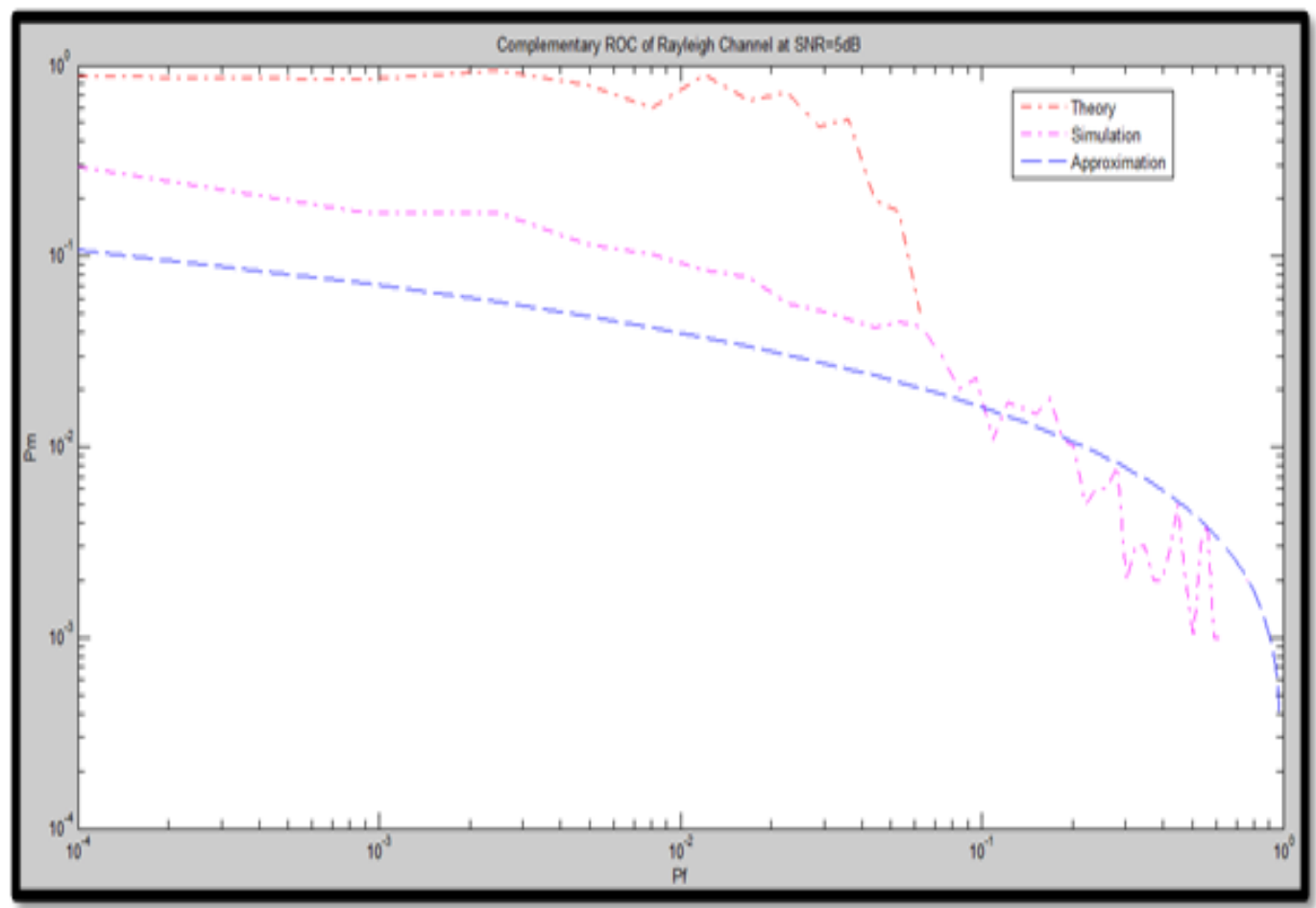

Figure 13. PM versus PF for Rayleigh Channel at SNR=5dB 


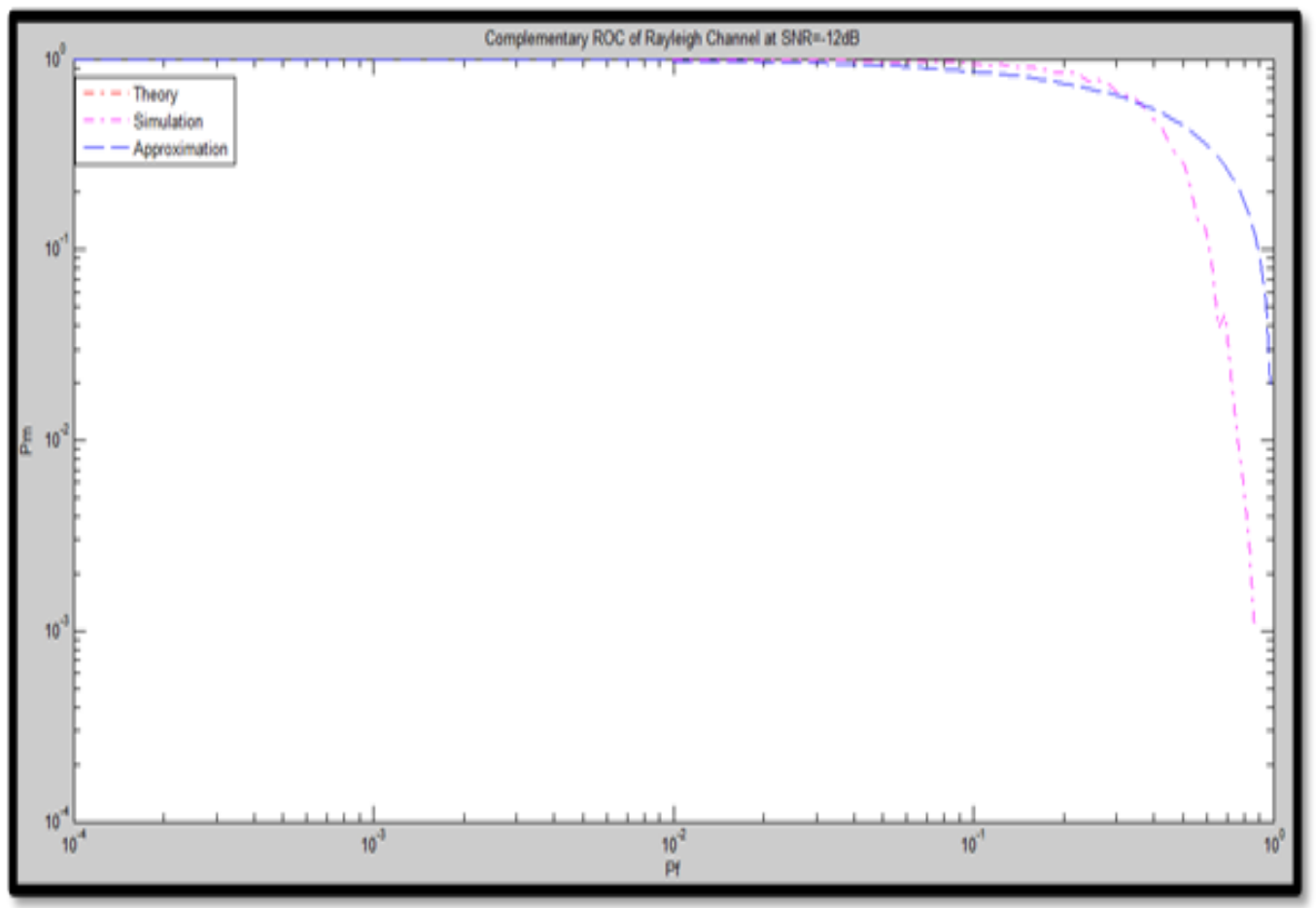

Figure 14. Pm versus Pf for Rayleigh Channel at SNR=-12dB

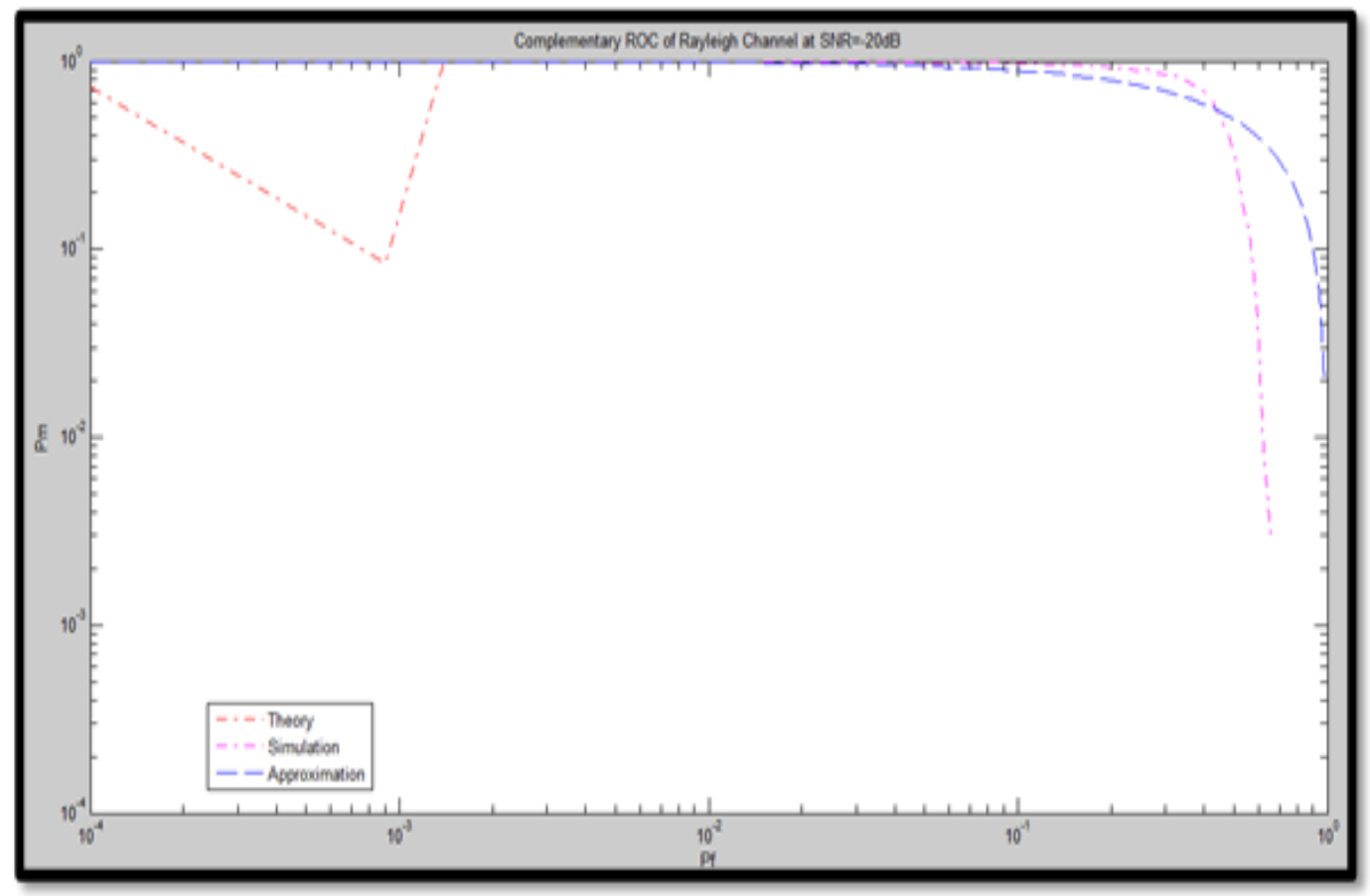

Figure 15. Pm versus Pf for Rayleigh Channel at SNR=-20dB 
Table 9. Probability of Missed Detection versus Prob of False Alarm Calculations for Different SNR Values (Rayleigh Channel)at Constant Probability of False Alarm value lying between $10^{-4}<\mathrm{P}_{\mathrm{f}}<10^{0}$ (i.e. 0.0001 to 1), with Number of Iterations $=10^{\wedge} 3$

\begin{tabular}{|l|l|}
\hline SNR(dB) & Probability of Missed Detection \\
\hline-20 & $0.7-0.005\left(10^{-0.3}<\mathrm{P}_{\mathrm{m}}<10^{-2.5}\right)$ \\
\hline-12 & $1-0.0001\left(10^{-3}<\mathrm{P}_{\mathrm{m}}<10^{0}\right)$ \\
\hline-5 & $0.5-0.001\left(10^{-0.5}<\mathrm{P}_{\mathrm{m}}<10^{-2.7}\right)$ \\
\hline 0 & $0.9-0.0009\left(\right.$ Less than $10^{0}<\mathrm{P}<$ Less than $10^{-3} \mathrm{~m}$ \\
\hline 5 & $0.5-0.0009\left(10^{-0.5}<\mathrm{P}_{\mathrm{m}}<10^{-2.8}\right)$ \\
\hline
\end{tabular}

Figures 6-9 show ROC Curves for different probabilities of detection and false alarm have been analyzed for SNR varying from 0 to $20 \mathrm{~dB}$. Also, the time bandwidth product has been analyzed corresponding to different $L$ values of signal sensing samples. It has been observed that at a constant probability of false alarm, the probability of detection varies from 0.74 at $\mathrm{SNR}=5 \mathrm{~dB}$ for 20 sensing samples as compared to 0.99 at $\mathrm{SNR}=20 \mathrm{~dB}$ for 100 sensing samples, while the probability of missed detection varies as 0.26 at $\mathrm{SNR}=5 \mathrm{~dB}$ for 20 sensing samples to 0.1 at $\mathrm{SNR}=20 \mathrm{~dB}$ for 100 sensing samples which shows significant contrast from spectrum sensing point of view. It indirectly implies that the probability of false alarm is persistently low for this value which is a good trend. Using energy detection here for Rayleigh channel implies that for larger number of sensing samples, the probability of missed detection is low, hence ,probability of detection of primary signal above the threshold is high, which means the channel is busy and the spectrum is occupied otherwise during energy detection by secondary user for each random event, if the probability of energy detection is less than the signal threshold, than it implies that primary user is not detected and channel is found idle as the spectrum is unoccupied. Figures11-15 show the trend in Probability of Missed Detection versus Probability of False Alarm for SNR values in range-20dB to $+5 \mathrm{~dB}$ which clearly shows that for $10^{3}$ iterations, the Probability of False Alarm varies from $10^{-4}$ to $10^{0}$ which means from 0.005 to less than 1(i.e., 0.7) at $\mathrm{SNR}=-20 \mathrm{db}$ but the trend for $\mathrm{SNR}=-5 \mathrm{~dB}$ shows that the Probability of False Alarm is around $10^{-4}$ i.e., 0.0001 which is less than $10^{\circ}$ i.e. 1.This implies as we move from lower SNR values to higher SNR range, there is decrease in the probability of false alarm which is a good trend. Also, the probability of missed detection is less than $1(0.7)$ at $\mathrm{SNR}=-20$ as compared to $\mathrm{SNR}=-5$ where, $\mathrm{PMD}$ is around 0.5 to (0.001) which is again desirable trend.

\section{Conclusion}

The probability of detection versus SNR performance analysis using Energy Detection approach under AWGN channel for different M values with QPSK modulation has been done. The probability of False Alarm is calculated after running the simulations within SNR range of -16 to $-4 \mathrm{db}$ with set number of iterations $=10^{\wedge} 3$. Next section describes the performance analysis of Energy detection simulation under Rayleigh flat fading channel under the effect of L number of sensing samples and variable SNR to calculate the probability of false alarm and probability of missed detection for the number of iterations $=10^{\wedge} 3$ and $10^{\wedge} 5$ in the Monte Carlo simulations. Under complexity analysis for 
FBMC, the frequency responses for different $\mathrm{K}$ values have been plotted under modified Phydas prototype filter.

\section{Impact of Study}

The present research work has its strong impact on the design of Multirate Filter banks for cognitive radio communication under wireless domain. The study can be extended to the wireless networks through the application of efficient filter banks which can be further helpful for analysis and design of future wireless radio technologies.

\section{Future Scope of Present Work}

The work in this thesis is helpful in developing the system level simulation for Fifth Generation Wireless network. C-OQAM is enabler for next generation Cognitive radio network[12]. The flexible features of this system allow its expansion to realize more computationally efficient algorithms. Performance Comparison of FBMC proposed with its variants to be modified in future can be done. The Comparative Performance Analysis of Cognitive Radio under Different Modulation and Coding Techniques using advanced Transform Techniques can be done. Rician, Nakagami, Weibull fading channels are available to replace AWGN and Binary Symmetric channel models to simulate the system under mobility radio channel[13-14]. Performance higher than optimal can be achieved by incorporating more influential parameters of interest in system level simulation models using adaptive signal processing. Attempts should be made to develop newer models of CR on Lab View, System View within SNR range for Cognitive radio operation $-5 \mathrm{~dB}$ to $+40 \mathrm{~dB}$ [15-17].Radio Spectrum Management at Physical Layer CR still may not provide sufficient BW. The study can be extended to design algorithms that further improve coordination between the cells, higher coverage of network and higher interference reduction in a cognitive radio network[18-23]. The present work done has its significant impact on the design and development of FBMC cognitive radio under ubiquitous and pervasive environment for the enhancement of FBMC under fading channels[24-36]

\section{Acknowledgement}

The first Author is thankful to Dr. Jasvir Singh, Deptt ECE, GNDU for his valuable help and discussion on the topic. The authors are highly thankful to Panjab University Research Promotion Cell for its constant encouragement and motivation to the researchers working in the field of engineering science and technology.

\section{References}

[1] J. Mitola and G. Q. Maguire, "Cognitive Radios: Making Software Radios More Personal", IEEE Personal. Communication, vol. 6, no. 4, (1999), pp. 13-18

[2] A. Sahai and N. Hoven, "Some Fundamental Limits on Cognitive Radio", Proc. Allerton Conference, Monticello, (2004), pp. 1-11.

[3] S. Ball, "Consumer Applications of Cognitive Radio Defined Networks", Proc.IEEE, (2005), pp. 518525 .

[4] A. Sahin and I. Guvenc, "A Survey on Multicarrier Communications: Prototype Filters, Lattice Structures and Implementation Aspects", IEEE Communications Surveys \& Tutorials, vol. 16, no. 3, (2014), pp. 1312-1338.

[5] H. Zhang, "Spectral Efficiency Analysis in OFDM and OFDM/OQAM based Cognitive Radio Networks", IEEE 69th Vehicular Technology Conference, 2009. VTC Spring, (2009), pp. 1-5.

[6] R.W. Chang, "Synthesis of band-limited orthogonal signals for multichannel data transmission", The Bell System Technical J, (1966), pp. 1775-1796.

[7] J. Mitola and G. Q. Maguire, "Cognitive Radios: Making Software Radios More Personal", IEEE Personal. Communication, vol. 6, no. 4, (1999), pp. 13-18.

[8] B. F. Boroujeny, "Multicarrier communication techniques for spectrum sensing and communication in cognitive radios", IEEE Communication Magazine, vol. 46, no. 4, (2008), pp. 80-85. 
[9] H.-T. Chiang, "Design of Non Uniform Filter Bank Transceivers for Frequency Selective Channels" EURASIP Journal on Advances in Signal Processing, vol. 2007, pp. 1-12.

[10] L. Rosenbaum, "An Approach for synthesis of Modulated M-Channel FIR Filter banks Utilizing the Frequency-Response Masking Technique”, EURASIP Journal on Advances in Signal Processing, vol. 2007, (2007), pp. 1-13.

[11] D. S. Waldhauser and J A Nossek, "Multicarrier Systems and Filter Banks", Advances in Radio Science, vol. 4, (2006), pp. 165-169.

[12] P. Pratim Bhattacharya, "A Novel Opportunistic Spectrum Access for Applications in Cognitive Radio", Ubiquitous Computing and Communication Journal, vol. 4, no. 2, (2006), pp. 24-28.

[13] C. Kocks and A. Viessmann, "A Cognitive Radio Realization based on a Petri Net Approach", Proc. International Symposium on Wireless Communication Systems, (2010), pp. 1031-1035.

[14] Q. Zhang, "Towards Cognitive Radio for Emergency Networks", Chapter1, pp. 1-26.

[15] B. Saltzberg, "Performance of an efficient parallel data transmission system", IEEE Trans. Communication Technology, vol. 15, no. 6, (1967), pp. 805-811.

[16] B. F. Boroujeny, "Multicarrier communication techniques for spectrum sensing and communication in cognitive radios", IEEE Communication Magazine, vol. 46, no. 4, (2008), pp. 80-85.

[17] M. Renfors, "PHYDYAS:D5.1 Report", Tampere University of Technology, Finland.

[18] S. Ball, "Consumer Applications of Cognitive Radio Defined Networks", Proc. IEEE, (2005), pp. 518525.

[19] Q. Zhang, "Towards Cognitive Radio for Emergency Networks", Chapter1, pp. 1-26.

[20] S. Liu, "Capacity Comparison for Fading Channels under Average and Peak Interference Power Constraints in Underlay Cognitive Radio System”, Proc.Stanford.edu, (2008), pp. 1-8.

[21] X. Kang and Y. C. Liang, "Optimal Power Allocation for Fading Channels in Cognitive Radio Networks under Transmit and Interference Power Constraints", Proc. IEEE International Conference on Communications ICC2008, (2008), pp. 3568-3572.

[22] M. Shaat, "Computationally Efficient Power Allocation Algorithm in Multicarrier- Based Cognitive Radio Networks", OFDM and FBMC systems", EURASIP Journal on Advances in Signal Processing, vol. 2010, (2010), pp. 1-13.

[23] Q. Peng and P.C. Cosman, "Analysis and Simulation of Sensing Deception in Fading Cognitive Radio Networks", Proc. 2010 IEEE, (2010), pp. 234-242.

[24] A.S. Kang and R. Vig, "Performance Analysis of Near Perfect Reconstruction Filter Bank in Cognitive Radio Environment", International Journal of Advanced Networking and Applications, vol. 8, no. 3, (2016), pp. 3070-3083.

[25] A. S. Kang and R. Vig, "Performance Analysis of FBMC-CR through Optimization -Tradeoff between Various Performance Parameters in the Cognitive Radio Environment", Telecommunication Systems, Springer, vol. 63, (2016), p. 23.

[26] A. S. Kang and V. Sharma, "Effect of Prototype Filter Length on PAPR Reduction and Side lobe tail attenuation on Autocorrelation in FBMC Cognitive Radio", International Journal of Advanced Information Systems \& Technology, University of Venezuela, vol. 51, (2016), pp. 38-48.

[27] A. S. Kang and R. Vig, "Comparative Performance Evaluation of Modified Prototype Filter Bank Multi Carrier Cognitive Radio under Constraints of Lp, K, N and D", The Computer Journal, Oxford University Press, UK, vol. 59, no. 3, (2016), pp. 1-13.

[28] A. S. Kang and R. Vig, "Comparative analysis of Energy Detection spectrum sensing of cognitive radio under Wireless Environment using SEAMCAT", International Journal of Advanced Computer Science and Applications(IJACSA), Science \& Information SAI Organization LTD,New York,USA, vol. 7, Issue 1, (2016), pp. 493-498.

[29] A. S. Kang and R. Vig, "K Coverage Probability of 5G Wireless Cognitive Radio Network under Shadow Fading Effects", Indonesian Journal of Electrical Engineering and Informatics (IJEEI), vol. 4, no. 3, (2016), pp. 181-188.

[30] A. S. Kang and R. Vig, "Performance Analysis of Effect of Sub Nyquist-Sampling on Multi Rate Filter Bank Cognitive Radio", Invertis Journal of Science \&Technology, vol. 8, no. 4, (2015), pp. 181-201.

[31] A. S. Kang and R. Vig, "Simulation Analysis of Prototype Filter Bank Multicarrier Cognitive Radio under different Performance Parameters", INDONESIAN Journal of Electrical Eng. \& Informatics, vol. 3, no. 3, (2015), pp. 157-166.

[32] A. S. Kang and R. Vig, "Computer Aided BER Performance Analysis of FBMC Cognitive Radio for Physical Layer under the Effect of Binary Symmetric Radio Fading Channel”, SPRINGER Journal of Wireless Personal Communications, NETHERLANDS, vol. 81, no. 2, (2015), p. 15.

[33] A. S. Kang and R. Vig, "BER Performance Analysis of Filter Bank Multicarrier Using Sub band Processing for Physical Layer Cognitive Radio”, Journal of Electrical \& Electronic Systems, UK, vol. 3, Issue 3, pp. 1-8.

[34] A. S. Kang, "Cooperative Sensing for Cognitive Radio: A Powerful Access Method for Shadowing Environment”, SPRINGER Journal of Wireless Communications, vol. 80, (2014), p. 16.

[35] A.S. Kang and R. Vig, "Computational Complexity Analysis of FBMC-OQAM under Different Strategic Conditions", Proc.IEEE -2014 RAECS UIET Panjab University Chandigarh, 978-1-47992291-8/14/\$31.00 (C2014 IEEE, (2014), pp. 1-6. 
[36] A. S. Kang and R. Vig, "Study of Filter Bank Multicarrier Cognitive Radio under Wireless Fading Channel", Proc.IEEE-IACC2014, International Advance Computing Conference, held at ITM University Gurgaon, 978-1-4799-2572-8/14/\$31.00_c 2014 IEEE, (2014), pp. 209-214.

\section{Authors}

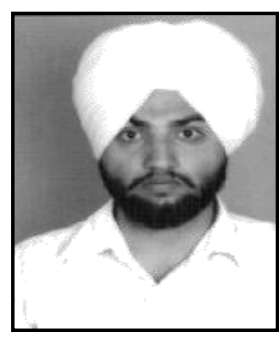

A. S. Kang, he did his B. Tech in Electronics \& Communication from Guru Nanak Dev University Amritsar in 2007 followed by M. Tech Degree in Electronics \& Communication Engg from Panjab University Chandigarh with University Merit Certificate in 2009. Thereafter he joined Dr.BR Ambedkar NIT Jalandhar for a short period and later joined Panjab University as Asstt Prof in ECE in 2009.He did his $\mathrm{PhD}$ in the field of cognitive radio communication from Deptt of UIET, Panjab University Chd in 2016. He has to his credit 07 IEEE and 01 Elseveir Conference Publication till date. Also, he has 26 Paper Publications at various International Journals of Repute from Countries of India, USA, UK, Russia, Germany, Pakistan and Portugal including Springer. $\mathrm{He}$ has one publication at Panjab University Research Journal (Sciences) and has guided several M. Tech Thesis Dissertations in the field of Communication Signal Processing. He has qualified the first National Mathematics Olympiad, New Delhi in year 2000.He has been an External Reviewer for Proposal Title Analysis, Design and Implementation of Nyquist Pulses in Next Generation Wireless Communication Systems submitted to the 2014 Initiation into Research. (National Fund for Scientific \&Technological Development of Chilean National Commission for Scientific and Technological Research CHILE, Aug 2014. He has even participated in "India-France Technology Summit" organized by DST, Govt of India, New Delhi 2014. He is a Life Member of IETE(NewDelhi), IAENG(HongKong), $\mathrm{He}$ can be contacted at askang_85@yahoo.co.in

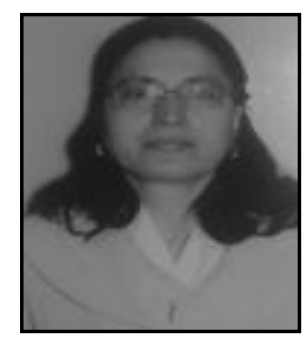

Renu Vig, she holds B.E in Electronics and Comm Engg followed by M.E and $\mathrm{PhD}$ degrees from Punjab Engg College, Chd(PANJAB UNIV CHD) .She worked as an Engg Educator at at various reputed institutions namely NITTTR Chd, PEC Chd for the past more than 25 years. At present she is working as Professor of Electronics \& Communication at Deptt UIET, Sc-25 PU chd with an Additional Charge of Director, UIET. She has to her credit many paper publications in International journals of repute beside a large number of Publications in IEEE International Conferences held in India and abroad. She has guided several M.E/M.Tech student Dissertations in joint collaboration with CSIO Chandigarh and many students are enrolled and registered for their $\mathrm{PhD}$ work under her Dynamic Leadership and Guidance. She has been awarded with Sir Thomas Medal by IE, India for her meritorious research work. She has been a source of motivation and courage to all the young scientists working in the field of Wireless \& Mobile Communication, Digital Signal Processing, Image Processing, Neural Network Fuzzy logic based Inelligent approach, Data Communication and Computer Networks. She has even authored a text book on the Principles of Electronics. Her Current research 
areas include Communication Signal Processing and Cognitive Radio Communication with special emphasis on wireless sensor networks.

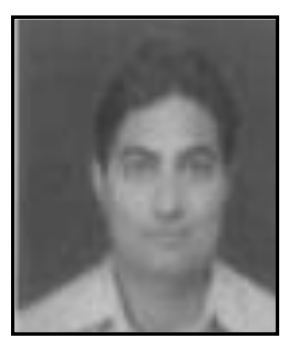

Vishal Sharma, he did his B.Tech in ECE from Nagpur University in year 2000.Thereafter he completed his Masters in Technology form Thapar Institute of Engg \& Technology in 2003.At Present he working as Asstt Prof in ECE at Deptt UIET, Panjab University Chandigarh since 2005. His areas of interest include Wireless Communication and Microelectronics .He can be contacted at vishaluiet@yahoo.co.in. He has attended many refresher and short term courses in the field of DSP and Communication throughout India from 2006 till date. 